\title{
Formation of santonide and parasantonide in the pyrolysis of santonic acid a new insight into an old reaction
}

\author{
E. Laura Moyano, ${ }^{\text {a }}$ Noelia M. Ceballos, ${ }^{\text {a }}$ Gloria I. Yranzo, ${ }^{* a}{ }^{a} u a n ~ Z i n c z u k, *{ }^{*}$ and Edmundo \\ A. Rúveda ${ }^{b}$ \\ ${ }^{a}$ Instituto de Investigaciones en Físico-Química de Córdoba (INFIQC) - Departamento de \\ Química Orgánica - Facultad de Ciencias Químicas - Universidad Nacional de Córdoba - \\ Ciudad Universitaria - 5016 Córdoba - Argentina \\ ${ }^{b}$ Instituto de Química Orgánica y de Síntesis (CONICET-UNR) - Facultad de Ciencias \\ Bioquímicas y Farmacéuticas - Suipacha 531- 2000 Rosario - Argentina \\ E-mail:yranzogi@dqo.fcq.unc.edu.ar; jzinczuk@fbioyf.unr.edu.ar
}

\section{Dedicated to Professor Rosa Lederkremer on her $70^{\text {th }}$ anniversary}

\begin{abstract}
Thermal reactions of santonic acid (1) in solution and flash vacuum pyrolysis were carried out in order to study the mechanism of formation of parasantonide (3) and santonide (4). Heating an acetic acid solution of $\mathbf{1}$ in a sealed tube at $200^{\circ} \mathrm{C}$ led to 3 , while heating at $175{ }^{\circ} \mathrm{C}$ afforded 4 . Flash vacuum pyrolysis of 1 was carried out between 300 and $550{ }^{\circ} \mathrm{C}, 10^{-2}$ torr and contact times of $10^{-2} \mathrm{~s}$. Results showed that $\mathbf{1}$ decomposed by at least two different mechanisms. One involving isomerization and lactonization affording 4 which affords 3 and the other involving radical scission and formation of aromatic and conjugated products. A mechanism involving isomerization to isosantonic acid (6) previous to lactonization is proposed for formation of 4.
\end{abstract}

Keywords: Flash vacuum pyrolysis, santonic acid, santonide, parasantonide

\section{Introduction}

The santonides, santonide and parasantonide, are isomeric neutral substances that were obtained by acidic reflux and thermolysis of santonic acid (1). ${ }^{1}$ While these compounds were obtained at the end of the 19th century by the Italian school led by Cannizzaro during their classical studies on the structure of the sesquiterpene santonin (2), ${ }^{2}$ their structures were not elucidated until 1950 when Woodward and Kovach reported a detailed description of the transformation of santonic acid into parasantonide and furthermore, proposed its structure as 3 . These authors also established that the configuration at $\mathrm{C}-11$ of $\mathbf{3}$ is opposite to the one in the same carbon of 
santonic acid (1) and further suggested that santonide (4) is the corresponding diastereoisomer (Figure 1). ${ }^{3}$

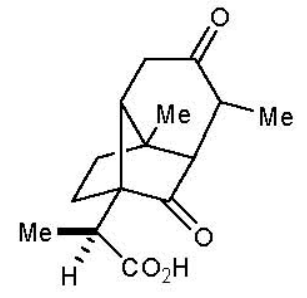

1

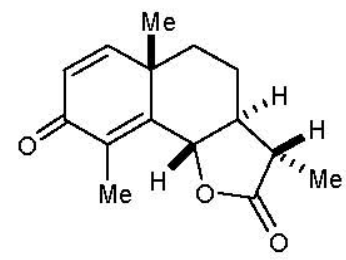

2

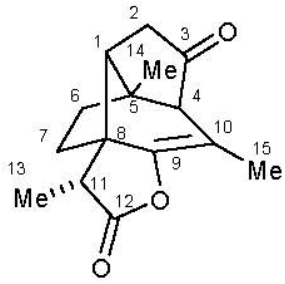

3

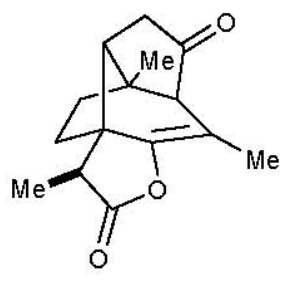

4

\section{Figure 1}

Although some of the transformations of $\mathbf{1}^{4}$ have been studied after the pioneering series of publications of Woodward et al., ${ }^{1 \mathrm{a}, 3}$ to the best of our knowledge, no additional reports exist in the literature on the transformation of $\mathbf{1}$ into $\mathbf{3}$ and $\mathbf{4}$ and on the confirmation of their structures. We have recently confirmed the complete structure of $\mathbf{3}$ and that of its alkaline hydrolysis product, parasantonic acid (5) (Figure 2), by X-ray crystallographic analysis, ${ }^{5}$ and, we wish to report now, a careful analysis of the transformation of $\mathbf{1}$ into $\mathbf{3}$ and $\mathbf{4}$ by static pyrolysis and flash vacuum pyrolysis.

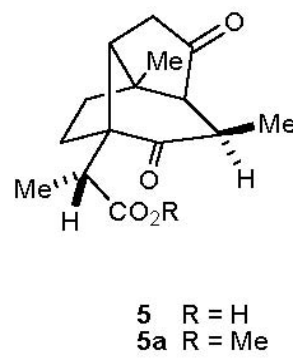

\section{Figure 2}

\section{Results and Discussion}

For the preparation of parasantonide (3) from (-)-santonic acid (1) we initially followed the procedure described by Woodward and Kovach. ${ }^{3}$ Instead of the direct isolation of $\mathbf{3}$ from the crude thermolysis product, we found more convenient, as the authors suggested, first to obtain crystalline methyl parasantonate (5a) (Figure 2) which, upon saponification to 5 and followed by treatment with acetic anhydride under reflux, afforded crystalline 3 . All our attempts to prepare santonide (4) by heating an acetic acid solution of $\mathbf{1}$ in a sealed tube at $200^{\circ} \mathrm{C}$, as described by Francesconi ${ }^{6}$ led to 3 . In our hands, this procedure proved to be more convenient for the preparation of $\mathbf{3}$ than those previously described. However, when we followed the procedure of 
Cannizaro and Valente ${ }^{7}$ [heating in vacuum at $175^{\circ} \mathrm{C}$ for $4 \mathrm{~h}$ the residue obtained of an acetic solution of 1 that had been heated at reflux for $18 \mathrm{~h}$ ] 4 was obtained in 22\% yield (based on the recovered santonic acid), after crystallization from diisopropyl ether. These results showed a broad trend in which the formation of $\mathbf{4}$ is favored at lower temperatures and that at higher temperatures, $\mathbf{4}$ equilibrates to 3 .

In order to follow the progress of the transformation of santonic acid (1) into santonide (4) and parasantonide (3), we conducted an experiment in a sealed NMR tube by heating a solution of 1 in acetic- $d_{3}$ acid $d_{1}$ at $200^{\circ} \mathrm{C}$. At different intervals, the reaction was monitored by ${ }^{1} \mathrm{H}$ NMR based on the signals of the Me-15 of 3 and 4 at $\delta 1.63$ and 1.65, respectively. After $2 \mathrm{~h}$ of heating, the exclusive formation of 4 was detected, whereas after $4 \mathrm{~h}$ and $6 \mathrm{~h}$, approximately 2:1 and 1:2 mixtures of $\mathbf{4}$ and $\mathbf{3}$ were observed. The geometries of $\mathbf{3}$ and $\mathbf{4}$ were fully optimized at B3LYP level using the standard 6-31G* basis set and the relative energies were calculated. ${ }^{8}$ The calculations showed that $\mathbf{4}$ is, in fact, less stable $\left(2.2 \mathrm{Kcal} \mathrm{mol}^{-1}\right)$ than $\mathbf{3}$. From this it is reasonable to propose that $\mathbf{4}$ is formed under kinetic control whereas $\mathbf{3}$ is the product of thermodynamic control or that $\mathbf{3}$ is formed from $\mathbf{4}$.

To have more information on these transformations, some flash vacuum pyrolysis (fvp) experiments were carried out. The characteristics of fvp allow one to obtain kinetic control products and/or to avoid further transformations as products leave the hot zone in a short time. Thus, fvp reactions of 1 were studied between 300 and $550{ }^{\circ} \mathrm{C}$ with pressures of $\sim 10^{-2}$ torr and contact times of $\sim 10^{-2} \mathrm{~s}$. At $550{ }^{\circ} \mathrm{C}$ no more santonic acid was detected in the reaction products. In almost all of the reactions nitrogen was used as carrier gas and in some reactions toluene was used as carrier in order to check for the presence of radicals. Products arising from different competing reactions were detected or isolated. Thus, isomerization, radical scission, lactonization and decarboxylation reactions were found. Reactions affording parasantonide (3) and santonide (4) will be discussed first, as they are the focus of this study. FVP reactions of 1 at $300-400{ }^{\circ} \mathrm{C}$ afforded small amounts of two isomeric products in the analysis by GC/MS. One of them was identified as isosantonic acid (6) by comparison with pure sample. It is worth noting here that pure $\mathbf{6}$ decomposed to an isomeric product in the column chromatography so, it was assumed that $\mathbf{1}$ isomerizes to $\mathbf{6}$ under fvp conditions at lower temperatures. A possible isomerization mechanism, reminiscent of the Dowd-Beckwith ring expansion, ${ }^{9}$ is depicted in Scheme 1.

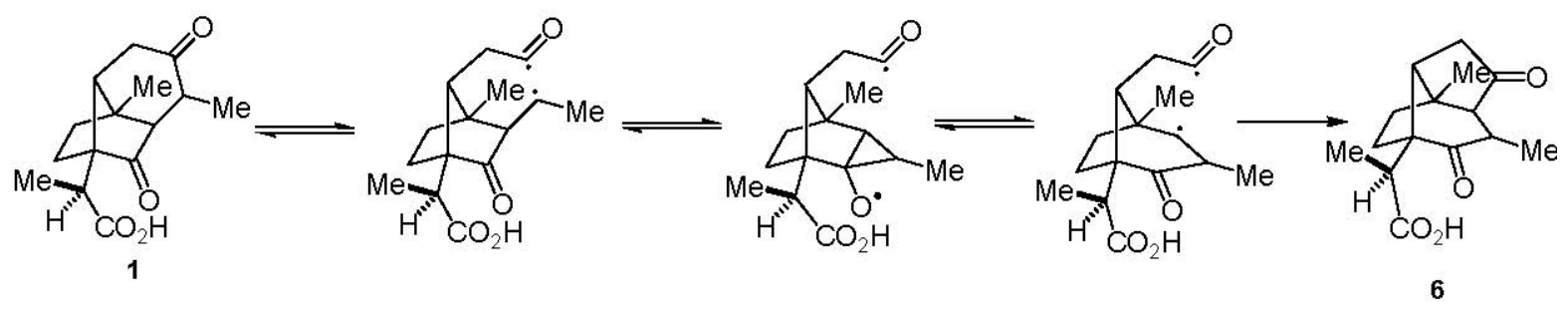

\section{Scheme 1}


It should be recalled that the mass spectra of 5 and 6 show an important peak of $\mathrm{m} / \mathrm{z} 246$ (lactone) and a low intensity peak of the molecular weight ( $\mathrm{m} / \mathrm{z} 264)$, while the mass spectrum of 1 has an important peak of the molecular weight and a small peak of the lactone. These results support the suggestion of Woodward et al. ${ }^{3}$ on the difficulties for lactonization of $\mathbf{1}$ due to structural impediments.

Parasantonide (3) and santonide (4) appeared in reactions over $400{ }^{\circ} \mathrm{C}$ with no traces of isosantonic acid (6), showing that under these conditions, 6 readily lactonizes to 4 (Scheme 2). At this point it was necessary to find out how parasantonide is formed, i.e., from isosantonic acid or from santonide. By solution experiments described above it was demonstrated that $\mathbf{3}$ is formed at higher temperatures than 4.

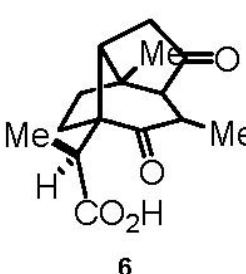

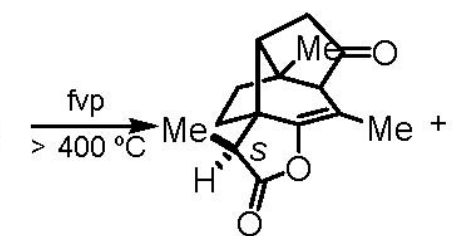

4

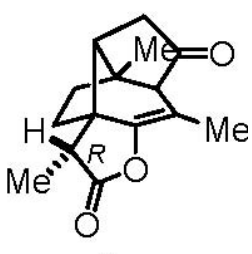

3

\section{Scheme 2}

The analysis by ${ }^{1} \mathrm{H}-\mathrm{NMR}$ and TLC showed that the yield of $\mathbf{4}$ was higher than $\mathbf{3}$, confirming that the former is the first lactonization product. To get more information on these reactions some fvp experiments of $\mathbf{3}$ and $\mathbf{4}$ were carried out at $500{ }^{\circ} \mathrm{C}$. Results are shown in Table 1; relative amounts were calculated by ${ }^{1} \mathrm{H}-\mathrm{NMR}$. It is worth noting here that no other products were detected in these reactions, showing that all of the products in fvp of $\mathbf{1}$, coming from radical and diradical reactions (that will be discussed later), arise from decomposition of $\mathbf{1}$ and not from $\mathbf{3}$ and 4. No evidence of bibenzyl was found when reactions were carried out with toluene as carrier gas, confirming that there are no radicals in the reaction.

Table 1. Flash vacuum pyrolysis of 4 and 3 at $500^{\circ} \mathrm{C}$

\begin{tabular}{cc}
\hline Starting Material & Product (\% yield) \\
\hline 4 & $3(42)$ \\
3 & $4(8)$ \\
\hline
\end{tabular}

As it can be seen in Table 1, 3 and $\mathbf{4}$ interconvert under the experimental conditions. Formation of $\mathbf{3}$ is clearly favoured, showing that this one may be the more stable isomer (as shown by calculations described above). This interconversion reaction can be explained by the mechanism depicted in Scheme 3. 


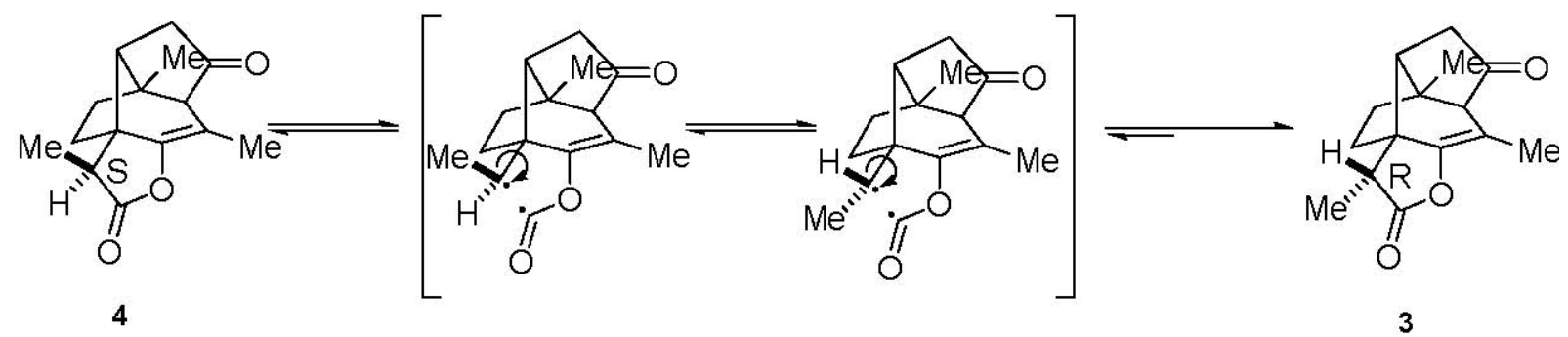

\section{Scheme 3}

This $\mathrm{C}-\mathrm{CO}$ bond fission in the lactone affording a diradical was already described in fvp reactions of $\alpha$-coumaranone leading to $\mathrm{CO}$ extrusion over $700^{\circ} \mathrm{C}$, although in this case it was an aromatic $\mathrm{C}-\mathrm{CO}$ bond fission. This rather unusual behavior was explained by thermochemical calculations. ${ }^{10}$ The interconversion reaction without $\mathrm{CO}$ extrusion can easily be explained because the reaction temperature is lower than the reported for $\alpha$-coumaranone.

As was mentioned earlier, fvp reactions of $\mathbf{1}$ are not as clean as desired, and above $450{ }^{\circ} \mathrm{C}$ some other competitive reactions also take place. So, products arising from decarboxylation $(\mathrm{m} / \mathrm{z})$ 220, from fragmentation $(\mathrm{m} / \mathrm{z}) 218$ and 190 and two other compounds with $\mathrm{m} / \mathrm{z} 246$ as 3 and 4 were formed as well. A description of these results and quantification of reactions at 470 and $500{ }^{\circ} \mathrm{C}$ are reported in Table 2; a tentative mechanism and structures of the different products are described in Scheme 4. Due to the fact that there are many isomeric products, they were separated as groups of compounds by polarity by column chromatography with different solvents (hexane/ethyl acetate 9:1, chloroform, ethyl acetate and methanol). The reported quantifications were done after separation of each fraction by preparative chromatography (hexane:ethyl acetate 9:1). 
Table 2. FVP of 1. GC/MS after column chromatography

\begin{tabular}{|c|c|c|c|}
\hline FVP Temperature $\left({ }^{\circ} \mathrm{C}\right)$ & \multicolumn{2}{|c|}{$\mathrm{m} / \mathrm{z}($ retention time $-\mathrm{s})$} & $\%$ \\
\hline \multirow{6}{*}{470} & $190(\mathbf{1 0}, \mathbf{1 1})$ & $(5.15 / 5.26)$ & 20.0 \\
\hline & $218+220$ & $(10.47 / 12.53 / 13.36)$ & 4.6 \\
\hline & $246(3,4)$ & (14.00) & 10.2 \\
\hline & 218 & $(13.14 / 13.52)$ & 9.2 \\
\hline & 246 & $(14.17 / 14.39)$ & 8.0 \\
\hline & Others $^{\mathrm{a}}$ & & 48.0 \\
\hline \multirow{6}{*}{500} & $190(\mathbf{1 0}-\mathbf{1 1})$ & & 12.0 \\
\hline & $218(7-9)+220$ & & 3.6 \\
\hline & $246(3,4)$ & & 33.6 \\
\hline & 218 & & 7.4 \\
\hline & 246 & & 6.4 \\
\hline & Others $^{\mathrm{a}}$ & & 37.0 \\
\hline
\end{tabular}

${ }^{a}$ Others: aromatic compounds such as indene, naphthalene and derivatives.

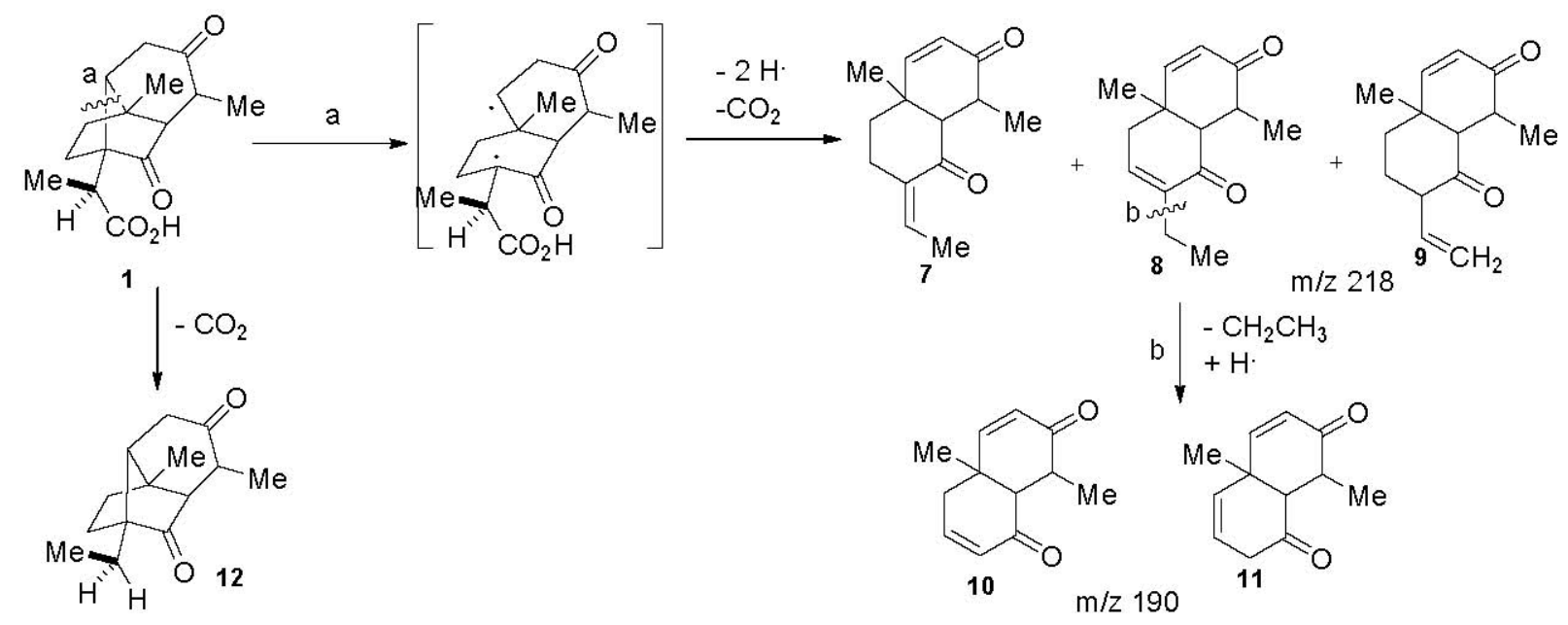

\section{Scheme 4}


The structures 7 - 11 agree with the many methyl and vinyl groups in the NMR spectrum and with the MS of each one after separation by GC/MS. These are typical fragmentations of cyclic compounds like terpenes taking place through different diradicals. ${ }^{11}$ Compound $\mathbf{1 2}$ is the expected product from decarboxylation of 1 . The presence of radicals was confirmed by the appearance of bibenzyl in reactions with toluene as carrier gas.

These parallel reactions should have been present in the experiments carried out by Woodward et al. ${ }^{3}$ since they reported only low yields of 3.

\section{Conclusions}

Here we have reported a new study of thermal reaction of santonic acid (1) leading to parasantonide (3) and santonide (4) . Under these conditions, 1 suffers parallel reactions coming from the different diradicals that can be formed. One of these paths leads to isosantonic acid (6) which lactonizes to $\mathbf{4}$. We have also demonstrated that $\mathbf{3}$ is formed from $\mathbf{4}$ by the radical opening of the lactone ring, epimerization of $\mathrm{C}-11$ followed by ring closure to the more stable isomer. The other products found come from decarboxylation and fragmentation of $\mathbf{1}$ by formation of different diradicals.

\section{Experimental Section}

General Procedures. Gas chromatography/mass spectrometry (GC/MS) analysis were performed with a $\mathrm{SE}$ - 30 column, using helium as eluent at a flow rate of $1 \mathrm{~mL} / \mathrm{min}$, the heating rate was different for each compound or mixture of compounds. Mass spectra were obtained in the electron impact mode (EI) using $70 \mathrm{eV}$ as ionization energy. ${ }^{1} \mathrm{H}-\mathrm{NMR}$ and ${ }^{13} \mathrm{C}-\mathrm{NMR}$ spectra were carried out in $\mathrm{CDCl}_{3}$ with a Bruker $200 \mathrm{FT}$ spectrometer (at $200 \mathrm{MHz}$ ) and in DMSO with Varian UNITY INOVA spectrometer $\left(200 \mathrm{MHz}\right.$ and $400 \mathrm{MHz}$ for ${ }^{1} \mathrm{H}$ and $100 \mathrm{MHz}$ for ${ }^{13} \mathrm{C}$ ). Chemical shifts are reported in ppm downfield from TMS. The IR spectra were recorded with a Thermo Nicolet AVATAR 320 FT-IR spectrophotometer. Melting Points were determined by a Büchi apparatus and are uncorrected. Column and thin layer chromatographies were performed on silica gel. Solvents were analytical grade.

\section{Compound characterization}

Preparation of parasantonide (3). Santonic acid (1) (2.64 g, $10 \mathrm{mmol})$ was dissolved in acetic acid $(15 \mathrm{~mL})$ and heated in a sealed tube at $200^{\circ} \mathrm{C}$ for $9 \mathrm{~h}$. The solvent was distilled off and the brown residue was extracted with $\mathrm{Et}_{2} \mathrm{O}(2 \times 30 \mathrm{~mL})$. The combined ethereal extracts were filtered and concentrated to give a brown oil $(915 \mathrm{mg})$ which was purified by a silica gel column chromatography with hexane: EtAcO (9:1) to give parasantonide (3) (527 mg, 21.5\% yield), mp $102-103^{\circ} \mathrm{C}$ (diisopropyl ether) (lit. ${ }^{7} 110-110.5^{\circ} \mathrm{C}$ ). This compound was also obtained by the procedure described by Woodward and Kovach ${ }^{3}$ : santonic acid was first converted into 
parasantonic acid (5) and then into parasantonide (3). ${ }^{1} \mathrm{H}$ and ${ }^{13} \mathrm{C}$ NMR data and HMBC correlations of 3 in $\mathrm{CDCl}_{3}$ at $500 \mathrm{MHz}$ and $125 \mathrm{MHz}$, respectively. The small differences in coupling constants $(7.3 \mathrm{~Hz}$ vs $7.1 \mathrm{~Hz})$ are probably due to the low digital resolution of the spectrometer.

\begin{tabular}{cccc}
\hline Position & $\delta_{\mathrm{C}}$ & $\delta_{\mathrm{H}}$, Multiplicity J $(\mathrm{Hz})$ & HMBC \\
\hline 1 & 47.04 & $2.21(1 \mathrm{H}, \mathrm{d}, 7.1)$ & $3,4,5,6,8,9,14$ \\
2 & 33.85 & $2.55(1 \mathrm{H}, \mathrm{d}, 18.9)$ & 3,5 \\
$2^{1}$ & & $2.29(1 \mathrm{H}, \mathrm{dd}, 19.0,7.0)$ & $1,3,8$ \\
3 & 208.56 & & \\
4 & 63.30 & $2.24(1 \mathrm{H}, \mathrm{s})$ & 10,15 \\
5 & 46.84 & & $1,4,5,14$ \\
6 & 29.65 & $2.08,1.60(\mathrm{~m})$ & $5,6,8,9$ \\
7 & 33.52 & $1.90,1.80(\mathrm{~m})$ & \\
8 & 53.91 & & $1,7,8,12,13$ \\
9 & 148.02 & & \\
10 & 102.30 & & 1,4 \\
11 & 36.51 & $2.69(1 \mathrm{H}, \mathrm{q}, 7.3)$ & $4,9,10$ \\
12 & 175.67 & & \\
13 & 8.57 & $1.18(3 \mathrm{H}, \mathrm{d}, 7.1)$ & \\
14 & 23.93 & $1.10(3 \mathrm{H}, \mathrm{s})$ & \\
15 & 12.52 & $1.63(3 \mathrm{H}, \mathrm{s})$ & \\
\hline
\end{tabular}

Preparation of santonide (4). Santonic acid (1) (2.64 g, $10 \mathrm{mmol}$ ) was dissolved in acetic acid $(15 \mathrm{~mL})$ and heated at reflux for $18 \mathrm{~h}$. The solvent was evaporated and the light brown residue was heated in vacuum at $175^{\circ} \mathrm{C}$ for $4 \mathrm{~h}$. The residue was dissolved in $\mathrm{Et}_{2} \mathrm{O}(25 \mathrm{~mL})$, washed with aqueous $10 \% \mathrm{Na}_{2} \mathrm{CO}_{3}$ solution $(2 \times 10 \mathrm{~mL})$, brine $(10 \mathrm{~mL})$, dried $\left(\mathrm{Na}_{2} \mathrm{SO}_{4}\right)$ and evaporated. The crude product $(660 \mathrm{mg})$ was purified by crystallization from diisopropyl ether to give pure santonide (4)[260 mg, 22\% yield (based on the recovered santonic acid, $1.37 \mathrm{~g}, 5.2 \mathrm{mmol}$, from the alkaline aqueous phase)], mp $129-130^{\circ} \mathrm{C}$ (lit. $\left.{ }^{7} 127^{\circ} \mathrm{C}\right) .{ }^{1} \mathrm{H}$ and ${ }^{13} \mathrm{C}$ NMR data and HMBC correlations of 4 in $\mathrm{CDCl}_{3}$ at $500 \mathrm{MHz}$ and $125 \mathrm{MHz}$, respectively: 


\begin{tabular}{cccc}
\hline Position & $\delta_{\mathrm{C}}$ & $\delta_{\mathrm{H}}$, Multiplicity J (Hz) & HMBC \\
\hline 1 & 46.73 & $2.33(1 \mathrm{H}, \mathrm{d}, 7.1)$ & $3,4,5,8,9,14$ \\
2 & 36.46 & $2.55(1 \mathrm{H}, \mathrm{d}, 19.2)$ & $3,5,8$ \\
$2^{1}$ & & $2.43(1 \mathrm{H}, \mathrm{dd}, 19.2,7.0)$ & $1,3,8$ \\
3 & 208.42 & & \\
4 & 63.57 & $2.24(1 \mathrm{H}, \mathrm{s})$ & $1,9,10$ \\
5 & 48.86 & & \\
6 & 30.07 & $2.10,1.60(\mathrm{~m})$ & $4,7,14$ \\
7 & 41.72 & $1.90,1.80(\mathrm{~m})$ & $5,6,8,9$ \\
8 & 52.89 & & \\
9 & 149.13 & & \\
10 & 101.86 & & \\
11 & 41.44 & $2.66(1 \mathrm{H}, \mathrm{q}, 7.8)$ & $7,8,12,13$ \\
12 & 176.66 & & $4,4,5,6$ \\
13 & 14.17 & $1.32(3 \mathrm{H}, \mathrm{d}, 7.95)$ & 4,10 \\
14 & 23.86 & $1.09(3 \mathrm{H}, \mathrm{s})$ & \\
15 & 12.70 & $1.65(3 \mathrm{H}, \mathrm{s})$ & \\
\hline
\end{tabular}

Preparation of isosantonic acid (6). Santonide (4) (2.46 g, $10 \mathrm{mmol})$ was treated with concentrated $\mathrm{HCl}(12 \mathrm{~mL})$ and after $15 \mathrm{~min}$ of heating at reflux, the solution was evaporated to dryness and the residue was crystallized from diisopropyl ether to give isosantonic acid (6) (2.25 g, $85 \%) \mathrm{mp} 151^{\circ} \mathrm{C}$ (Lit. ${ }^{6} 152^{\circ} \mathrm{C}$ ).

\section{General flash vacuum pyrolysis experiments}

Flash vacuum pyrolysis reactions were carried out in a vycor glass reactor using a Thermolyne 21100 tube furnace with a temperature controller device. Oxygen-free dry nitrogen was used as carrier gas. Samples to be pyrolyzed were of $\sim 40 \mathrm{mg}$. Contact times were around $10^{-2} \mathrm{~s}$ and pressures of 0.02 Torr were used. Products were trapped at the liquid air temperature, extracted with solvent and submitted to different analysis or separation techniques.

\section{Flash vacuum pyrolysis of 1}

Reactions of 1 were carried out between 300 and $550{ }^{\circ} \mathrm{C}, 10^{-2}$ torr and contact times of $\sim 10^{-2} \mathrm{~s}$. Reaction crudes were extracted with chloroform and submitted to GC/MS, column chromatography and/or preparative chromatography and ${ }^{1} \mathrm{H}-\mathrm{NMR}$.

Products of m/z 218 (7 - 9). GC/MS (\%): a) 218 (M+, 24), 133 (100), 107 (99), 106 (50), 105 (48), 91 (63), 82 (47), 79 (52), 77 (39), 67 (46). b) 218 (M+, 45), 175 (63), 135 (45), 95 (52), 91 (59), 79 (45), 77 (56), 67 (100), 55 (49), 53 (58); c) $218\left(\mathrm{M}^{+}, 58\right), 124$ (65), 107 (46), 95 (46), 91 (50), 79 (51), 77 (55), 67 (100), 55 (43), 53 (58). 
Products of m/z 190 (10 - 11). GC/MS (\%): a) $190\left(\mathrm{M}^{+}, 100\right), 175$ (96), 119 (70), 106 (44), 105 (61), 91 (62), 81 (43), 79 (57), 77 (48), 53 (50). b) $190\left(\mathrm{M}^{+}, 100\right), 175$ (72), 162 (72), 147 (71), 133 (63), 119 (84), 105 (71), 91 (71), 79 (70), 53 (67).

\section{Supplementary Information Available}

Include a sentence summarizing any Supplementary Information appearing with the Paper

\section{Acknowledgements}

We thank Drs Manuel González-Sierra and Gerardo Burton for NMR determinations and Dr Eugene Kovach for a generous gift of santonin. We also thank Lic. Natalia González for her helpful assistance in some fvp experiments. The work at IQUIOS was supported by Consejo Nacional de Investigaciones Científicas y Técnicas (CONICET) and Universidad Nacional de Rosario (UNR). The work at INFIQC was supported by Consejo Nacional de Investigaciones Científicas y Técnicas (CONICET), Fondo para la Investigación Científica y Tecnológica (FONCyT) and Universidad Nacional de Córdoba (UNC).

\section{References and Notes}

1. (a) Woodward, R. B.; Brutschy, F. J.; Baer, H. J. Am. Chem. Soc. 1948, 70, 4216. (b) Brunskill, A. P. J.; Thompson, H. W.; Lalancette, R. A. Acta Cryst. 1999, C55, 566. (c) For a recent account on the stories of santonin and santonic acid structures, see: Birladeanu, L. Angew. Chem. Int. Ed. 2003, 42, 1202.

2. For an early account of the chemistry of santonin see: Simonsen, J.; Barton, D. H. R. The Terpenes, Vol IIII; Cambridge University Press: New York, 1952; pp 249-322.

3. Woodward, R. B.; Kovach, E. G. J. Am. Chem. Soc. 1950, 72, 1009.

4. (a) Hortmann, A. G.; Daniel, D. S.; Schaefer, J. J.Org.Chem. 1968, 33, 3988. (b) Hortmann, A. G.; Daniel, D. S. J.Org.Chem. 1972, 37, 4446. (c) Niak, U. S.; Paknikar, S. K.; Bates, R. B.; Camou, F.A. Tetrahedron Lett. 1987, 28, 5641.

5. Zinczuk, J.; Rúveda, E. A.; Thompson, H. W.; Lalancette, R. A. Acta Cryst. 2004, C60, 408. That santonide (4) and isosantonic acid (6) are the diastereoisomers at $\mathrm{C}-11$ of parasantonide (3) and parasantonic acid (5) respectively, was confirmed by X-ray crystallographic analysis, Zinczuk, J.; Rúveda, E. A.; Thompson, H. W.; Lalancette, R. A. unpublished results.

6. Fransesconi, L. Gazz.Chim. Ital. 1895, 25ii, 461.

7. Cannizzaro, S.; Valente, L. Gazz.Chim. Ital. 1878, 8, 309. 
8. We thank Dr Silvina Pellegrinet for these calculations.

9. Ardura, D.; Sordo, T. L. Tetrahedron Lett. 2004, 45, 8691.

10. (a) Wentrup, C.; Müller, P. Tetrahedron Lett. 1973, 14, 2915. (b) Wentrup, C.; Tetrahedron Lett. 1973, 14, 2919.

11. Brown, R. F. C. In Pyrolytic Methods in Organic Chemistry, Academic Press, Inc.: New York, 1980; pp 166-250. 